\title{
New Extensive Anterior Myocardial Infarction by ECG Finding
}

National Cancer Institute

\section{Source}

National Cancer Institute. New Extensive Anterior Myocardial Infarction by ECG Finding. NCl Thesaurus. Code C102735.

An electrocardiographic finding of pathologic Q waves in leads $\mathrm{V} 1$ to $\mathrm{V} 6$, I and aVL, which is suggestive of myocardial infarction involving the anterior and anterolateral walls of the left ventricle and which is new compared to prior ECGs. (CDISC) 